\title{
Tuberous sclerosis complex: everything old is new again
}

\author{
Kevin C. Ess
}

Received: 16 February 2009 / Accepted: 23 April 2009 /Published online: 6 May 2009

(C) Springer Science + Business Media, LLC 2009

\begin{abstract}
Tuberous Sclerosis Complex (TSC) is a multiorgan genetic disease caused by loss of function of either the TSC1 (encodes hamartin) or TSC2 (encodes tuberin) genes. Patients with TSC have benign tumors (hamartomas) in multiple organs though brain involvement is typically the most disabling aspect of the disease as very high rates of neurodevelopmental disorders are seen. While first described well over 120 years ago, recent advances have transformed TSC into a prototypical disorder that exemplifies the methods and potential of molecular medicine. This review will detail historical aspects of TSC and its strong associations with neurodevelopmental disorders focusing on epilepsy and autism. Finally, promising new approaches for the treatment of epilepsy and autism in patients with TSC as well as those in the general population will be discussed.
\end{abstract}

Keywords Tuber $\cdot$ Autism $\cdot$ Epilepsy $\cdot$ mTORC1

\section{Introduction}

While recognized as a specific disease for well over 125 years, TSC has continued to intrigue and frustrate physicians, scientists and patients alike given its prominent

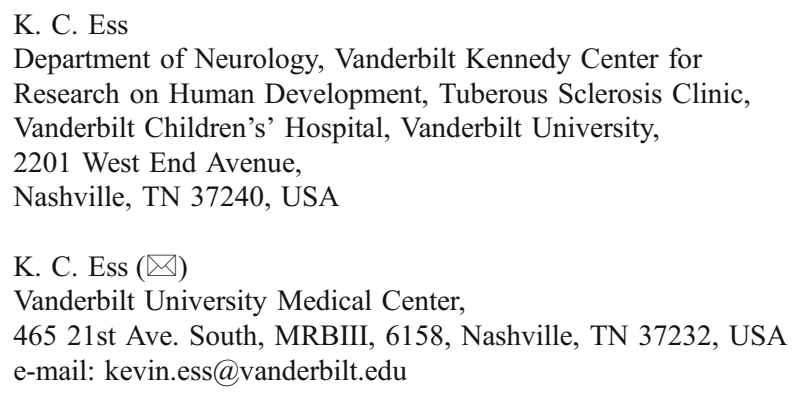

association with many organs of the body including brain, heart, kidney, skin and lung. Brain involvement however is most debilitating as intractable epilepsy, developmental delay and autism are seen in many patients. These features usually arise early in childhood and are typically resistant to existing therapies. Despite these many challenges, research over the past 15 years has flourished with seminal advances that include cloning of the TSC1 and TSC2 genes, identification of downstream signaling pathways, generation of relevant animal models and possibly even the development of new rational therapies. TSC should not be considered a rare disease. It has a worldwide incidence of approximately $1: 6,000$ births [1] and many people with this disorder have severe neurological manifestations [2]. Though it has been recognized as a distinct neurocutaneous disease for many years with a close association between epilepsy, autism, developmental delay and psychiatric problems, the importance of TSC also lies as a prototypical neurodevelopmental disorder. In this sense TSC serves as an excellent example of the power of molecular based technologies to define disease mechanisms. Advances in TSC will continue and should offer further important lessons for many genetic diseases affecting brain development, epilepsy, cognition and social function.

\section{Neurological manifestations}

Epilepsy

Epilepsy is seen in up to $90 \%$ of all patients with TSC during their lifetime [3]. This extraordinary prevalence affects all aspects of brain dysfunction in TSC and highly impacts the quality of life of these patients as well as their families. Multiple seizures types are seen in TSC though 
complex partial and primary generalized seizures are the most common. Of note, infantile spasms are seen up to 50 $60 \%$ of patients $[4,5]$ making TSC likely the most common known genetic cause of these often devastating seizures. Infantile spasms merit special attention given this high prevalence but also because these seizures may be the first manifestation of TSC in undiagnosed patients. Thus, all children presenting with infantile spasms should undergo a thorough evaluation including examination of the skin and MRI imaging of the brain (see Fig. 1). In addition, children with infantile spasms from TSC can usually be very successfully treated with the medication vigabatrin [6]. This drug raises brain levels of GABA, the main inhibitory neurotransmitter of the cerebral cortex. In contrast to other causes of infantile spasms, the rapid and usually complete response to vigabatrin suggests that infantile spasms in TSC may be due to abnormalities of GABAergic interneurons. This potential mechanism is of great interest as current theories of the pathogenesis of both epilepsy and autism in the general population prominently feature abnormalities of GABAergic interneuron differentiation and/or function [7].

The very high prevalence of epilepsy makes any assessment of neurodevelopmental disorders in patients with TSC particularly challenging and raises several questions. Are patients actively having seizures? If so, how often and from what region of the brain? Are there cognitive or other side effects from medications used to treat seizures? Despite these confounding factors, epilepsy alone does not account for all problems in TSC and demands further inquiry to determine why neurological comorbidities are seen at such high rates [8].

\section{Autism}

The association of autistic behaviors with TSC was first noted many years ago ([9] and see section below). Using detailed assessments, a diagnosis of autism is seen in approximately $25 \%$ of patients and an autism spectrum disorder (ASD) in another 25\% [10, 11]. Of note, autism and ASD are commonly seen in conjunction with epilepsy in patients with TSC though this is not an absolute association. Furthermore, autism and ASD in TSC are seen in males and females at similar rates standing in marked contrast to the male predominance seen in the general population with autism [12]. The association of autism in patients with TSC remains poorly understood but may be impacted by seizures at a young age, the presence and location of cortical malformations, abnormalities of cellular signaling pathways or other mechanisms that are currently unknown. This intimate relationship between TSC and autism will be

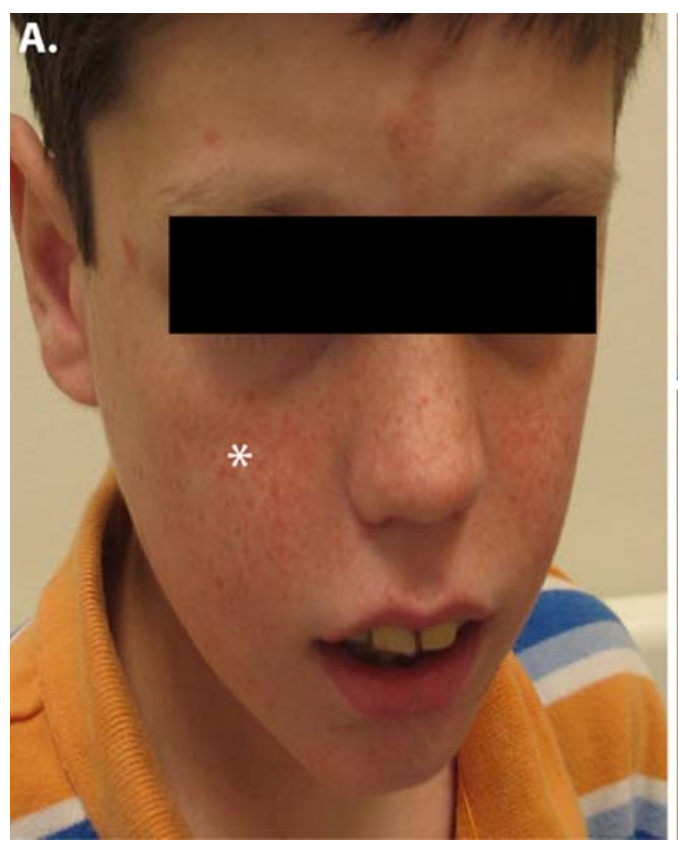

Fig. 1 Skin and brain abnormalities in patients with TSC. a Facial angiofibromas are found in many children with TSC. While they begin as flat red macules on the face, they progress to raised red papules $(*)$ that tend to spread over the cheeks and nose in a distinctive manner. b Shagreen patches (raised irregular skin lesions) are often found on the lower back. They are not usually seen in young children but can be a specific sign of TSC in older children and adults.
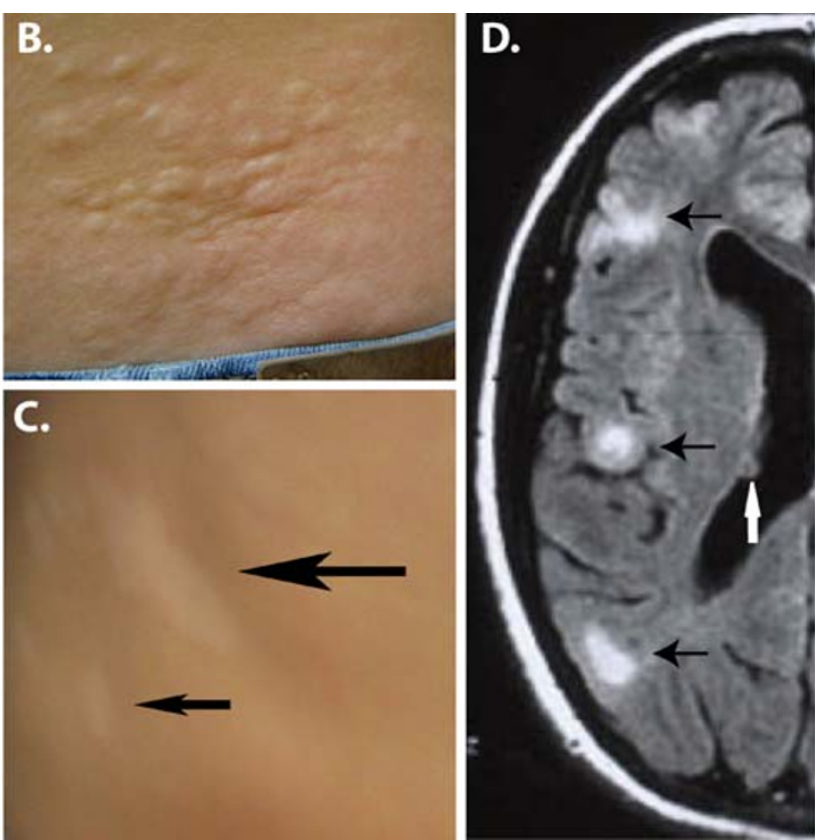

c Hypopigmented macules (Ash Leaf spots) are the most common skin abnormality in TSC and can be seen even at birth. The typically have an irregular appearance with most patients having $>5$ lesions. d FLAIR (Fluid Inversion Recovery) MRI images of the brain show both tubers (black arrows) and SEN (white arrows). Patient photographs by author obtained with consent 
revisited several times during this review focusing on new findings that may pertain to the general population of children with autism who do not have TSC.

Additional neurological manifestations

Children with TSC have developmental delay that typically manifests during the first year of life. As they age, frank mental retardation with permanent cognitive deficits is seen in approximately one-half of patients with TSC [13]. Behavioral problems are also seen in many children with TSC and can be very challenging for caregivers. Even children who appear to have normal or near normal intelligence often have exaggerated presentations of normal childhood behaviors. Other aspects of TSC not adequately recognized include anxiety disorders and depression that are frequently seen in young adults and adults with TSC irrespective of a history of cognitive delay or autism [14].

Despite this sobering description of the neurological manifestation of TSC, it should be kept in mind that 25$40 \%$ of patients with TSC have normal to near normal intelligence and function quite well [15]. Why such variability exists in TSC is not well understood but as detailed below remains an active area of research.

\section{Non-neurological manifestations}

In addition to brain, other organs are prominently involved in TSC. As befitting a neurocutaneous disease, skin involvement is very common and often leads clinicians to suspect the correct underlying diagnosis. Hypopigmented macules (also known as Ash Leaf spots) are seen in many patients with TSC (Fig. 1c). While not specific to TSC, even at birth multiple hypopigmented regions can be seen in very young children. However, they can be seen more readily after sun exposure to the normal appearing skin as hypopigmented macules usually do not tan. A Wood's light (UV) can also be employed in the clinic to aid in the identification of hypopigmented macules but in the opinion of the author this tool does not appreciably increase the sensitivity of detection. Other dermatologic manifestations include Shagreen patches (Fig. 1b) and angiofibromas (Fig. 1a, originally termed "adenoma sebaceum"). Shagreen patches are raised areas of the skin usually found in the lower part of the back and are relatively specific for TSC. Facial angiofibromas are often progressive lesions in older children and adults that can cause cosmetic as well as medical problems given their propensity to bleed. Overall, these skin manifestations are a minor aspect of the disease but their recognition can be critical for a correct underlying diagnosis and focusing attention to the potentially more severe manifestations of TSC.
Finally, patients with TSC often have abnormalities of heart, kidney and lung. Each of these manifestations has complex presentations that are beyond the scope of this review but have recently been thoroughly reviewed [2].

\section{Historical overview of TSC}

TSC has a relatively long history in the annals of medicine with important gains by numerous investigators (well summarized in [16]). TSC was initially reported in 1863 by Friedrich Daniel von Recklinghausen. Though he is best remembered for his later descriptions of neurofibromatosis, he is credited for the first report of hard (sclerotic) areas of the brain as well as heart tumors in a child who died in the neonatal period [17]. von Recklinhausen did not however recognize these abnormalities as a specific disorder. It was left to Désiré-Magloire Bourneville who between 1880 and 1900 published multiple reports that defined a distinct pathological entity in patients suffering from developmental disabilities and epilepsy [18, 19]. Like most medical therapies of this period, treatment options were limited for patients with epilepsy but included bromides, nitrates and even leeches! These therapies evidently were quite ineffective as Bourneville went on at autopsy to describe focal brain lesions in these patients. These lesions were evidently reminiscent of small potatoes ("tubers") leading Bourneville to coin the somewhat awkward term "sclérose tubéreuse" or tuberous sclerosis [18]. In addition to brain involvement, Bourneville also described associated abnormalities of kidneys and skin. This constellation of clinical findings were further expanded by Vogt in 1908 who suggested tuberous sclerosis be diagnosed in patients with developmental delay, epilepsy and cutaneous signs of "adenoma sebaceum" [20]. Of note, this so called "Vogt's triad" held sway for many years in the general perception and diagnosis of TSC. More recent studies have found that only about $30 \%$ of all patients actually fulfill these criteria underscoring an appreciation for the protean manifestations of TSC [21, 22]. Incremental gains in the understanding of tuberous sclerosis continued during the 20th century but was revitalized by Gomez in the 1960's and 1970's [23]. His studies greatly organized this field and paved the way for the development of molecular tools to define genetic etiologies that underlie tuberous sclerosis. Of note, the nomenclature also evolved over time with the extension "complex" added to emphasize the multi-organ nature of the disease and also distinguish it from the unrelated disorder multiple sclerosis [24]. The name tuberous sclerosis complex also serendipitously reflects contemporary knowledge that the TSC1 and TSC2 gene products function together as a complex and also inhibit the multiprotein complex mTORC1 (see below, Fig. 2). 


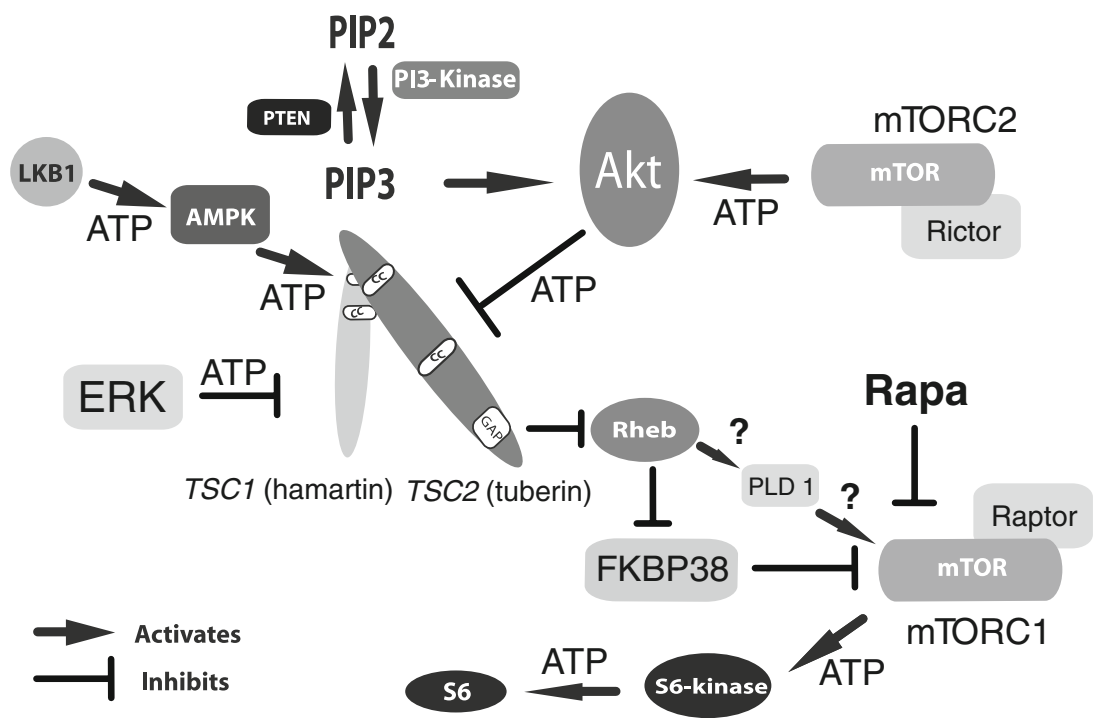

Fig. 2 Simplified Upstream and Downstream Signaling Pathways in TSC. Growth factors (not shown) bind to transmembrane receptors and lead to PI-3 Kinase activity causing an increase in PIP3 production leading to activation of AKT. AKT and/or ERK can then directly inhibit tuberin by phosphorylation. However, phosphorylation of tuberin by AMPK at other amino acid residues is activating. Hamartin binding seems to be required for stabilization and function of tuberin. Tuberin contains a C terminal GAP (GTPase activating protein) domain that inhibits the $G$ protein Rheb, an important activator of mTORC1. Intermediary steps are not completely

Of special historical note, MacDonald Critchley and Charles J.C. Earl (National Hospital, Queen Square London) in 1932 published a remarkable description of 29 patients with TSC [9]. This report describes quite well the clinical symptoms of what is now recognized as autism and autism spectrum disorders (ASD). Patients were reported to "appear vague and preoccupied and is mentally inaccessible" and "Speech which may have been fairly fluent now falls off, they use very few words and may show echolalia and short perseverative repetition of phrases, or may become almost entirely mute". Remarkably, these words were written at least 10 years before Leo Kanner first published his landmark study using the word autism to describe children with similar symptoms [25].

\section{Neuropathology}

Tubers

Tubers are quite readily detectable using modern MRI making the correct diagnosis of TSC fairly straightforward for most patients (Fig. 1d, tubers black arrows). Microscopic evaluation of tubers reveals many abnormal and large cells that express markers of both neuronal as well as glial cell differentiation [26]. These and other findings suggest that the TSC genes normally function during neural understood but may involve binding of FKBP38 [70] and/or enzymatic activity of PLD1 [71]. Loss of hamartin or tuberin function by mutation or inhibitory phosphorylation then allows constitutive activity of mTORC1 with subsequent increases of levels of phosphorylated ribosomal S6-kinase and phosphorylated ribosomal S6. How these alterations lead to the specific pathological changes in TSC is not well understood. Rapamycin (Rapa) and similar drugs potently inhibit mTOR activity within mTORC1. ATP indicates sites of phosphorylation by kinases. Figure modified from [72]

progenitor cell differentiation and regulate the production of both neurons and glial cells.

While gross and microscopic abnormalities have been reported in brains from patients with TSC for many years, there are still many questions about over how these lesions form and contribute to the neurological phenotypes that are seen. The consensus view is that tubers are responsible for cognitive impairment, seizure generation, behavioral disturbances and autism. There is some controversy about this point at least for seizure generation as tubers themselves can be electrically silent though abnormal discharges can be seen emanating from the immediately adjacent cortex [27]. Tubers arise during early brain development prior to 18 weeks of gestation; this has been substantiated by two autopsy studies of aborted human fetuses with TSC [28, 29]. Tubers should then considered to be cortical malformations that arise only during early fetal development and not postnatally. This view has been challenged by anecdotal reports of changes in the MRI appearance of tubers in children and adults with TSC. In addition to possible structural changes, tubers may alter epileptogenicity over time with previously quiescent lesions becoming sites of seizure origination.

The relationship of tubers to overall function, epilepsy and autism has been extensively studied though the published literature is not coherent with many contradictory studies. For example, autism was found to be highly 
correlated with tubers in the temporal lobes and particularly with patients with a history of temporal lobe seizures [30, 31]. This finding has not been replicated by other groups [32] though a strong association of cerebellar tubers with autism was noted [33, 34]. These discordant findings strongly suggest that other factors in addition to location of tubers determine the development of complex disorders such as autism. An important example is the growing body of work using mouse models of TSC that suggests that tubers are not required for neurological dysfunction. Using several "tuber-less" mouse models (see below) loss of $T s c 1$ or $T s c 2$ has recapitulated several important aspects of the TSC phenotype including epilepsy, cognitive problems and social impairment. These findings are difficult to reconcile with the overt brain abnormalities seen in the vast majority of patients with TSC. Additional animal models and technical approaches then are likely needed to define the primacy of tubers in the pathogenesis of tuberous sclerosis.

\section{SEN, SEGA}

In addition to cortical tubers, other structural brain lesions in TSC include subependymal nodules (SEN) (Fig. 1d, white arrow) and subependymal giant cell astrocytomas (SEGAs) (also known as a subependymal giant cell tumor, SGCT). As their names imply, these lesions are found immediately subjacent to ependymal layer lining the ventricles of the brain. SEN and SEGAs are likely very similar pathological entities that differ mainly by relative size and a propensity of SEGAs to grow. While they can be found throughout the lateral and third ventricles, they have a tendency to grow near the Foramen of Monro and become clinically important if continued growth in this region obstructs the flow of CSF leading to hydrocephalus. Fortunately, SEGAs are generally quite slow growing and can usually be identified by serial brain imaging prior to the development of hydrocephalus or other symptoms. Interestingly, SEGAs exhibit a limited window of growth that is almost always restricted to the first two decades of life. Analyses of SEGAs reveal expression of both neuronal and glial cell markers reminiscent of tubers $[35,36]$. The expression of glial cell markers however, predominates in SEGAs. While speculative, this may reflect their postnatal origin from neural progenitors that normally reside in the subependymal zone [37].

\section{Molecular genetics}

A genetic basis for TSC was first noted in 1913 by H. Berg who described multiple affected member of an individual family [38]. Additional pedigrees established an autosomal dominant pattern of transmission though the majority of patients appear to have a sporadic form of TSC. However, like many diseases, major advances in understanding TSC only occurred after the identification and cloning of the causative genes. Initial linkage studies using familial cases identified two independent loci on chromosomes 9 and 16 . The subsequent cloning of TSC1 (encodes hamartin) [39] and TSC2 (encodes tuberin) [40] genes and protein interaction studies led to the current model where hamartin and tuberin are obligate partners with both proteins required for full inhibition of downstream targets (see Fig. 2). TSC1 and TSC2 both encode large proteins that have extensive sequence conservation in widely divergent species. This suggests that there are other hamartin and tuberin specific functions that are not yet known. With this caveat, the current model of hamartin/tuberin function predicts that patients with $T S C 1$ or TSC2 mutation should have similar disease manifestations from loss of function of the entire hamartin/tuberin complex. While this is broadly true, patients with TSC2 mutations tend to have a more severe clinical course and are much less likely to have a family history of TSC [41]. Currently, a major issue in TSC research is whether the focal abnormalities in various organs originate from loss of the second allele of either the TSC1 or TSC2 gene. This would then be similar to the "two-hit" model of tumor suppressor function put forth by Knudsen [42] and like retinoblastoma suggests that while transmittable as an autosomal dominant disorder, it is autosomal recessive at the cellular level. Support for such a model has been definitively shown for kidney tumors in TSC but has been much more difficult to show in brain lesions [43]. This has led to speculation that cells with second hits are either very difficult to detect in tubers and SEGAs or that distinctive mechanisms of tuberin or hamartin inactivation including phosphorylation are at work in the brain. An additional possibility is that loss of one copy of either gene is sufficient to cause disease. This model of haploinsufficiency would predict hamartin/tuberin loss of function in every cell of the body including those in the brain. This last model is not congruent with clinical findings as focal brain lesions are always found adjacent to normal appearing cortex (see Fig. 1d). However, animal models have provided some support for haploinsufficiency as mice with one functional allele of the $T s c 1$ or $T s c 2$ genes have learning abnormalities in the absence of tuber-like lesions [44, 45].

\section{Signaling pathways}

While advances in molecular genetics transformed the field of TSC, the greatest catalyst was the placement of hamartin and tuberin within cellular signaling pathways. This work depended on the use of simpler model systems including yeast and Drosophila to identify hamartin/tuberin as upstream regulators of Rheb and mTOR (reviewed in 
[46]). These findings were rapidly confirmed in mammalian tissues and cells and extended to identify complex regulatory pathways with multiple upstream and downstream kinases (Fig. 2). These cascades culminate to control mammalian target of rapamycin (mTOR). This serine/ threonine kinase was already known to be a critical regulator of many important cellular processes [47]. mTOR is found with other defined binding partners as mTOR Complex 1 (mTORC1) or mTOR Complex 2 (mTORC2) that have distinct functions [48]. Of note, mTORC1 is potently inhibited by rapamycin while mTORC2 is much less sensitive. mTORC1 inhibitors have thus garnered much attention as possible new and rational therapeutics for TSC. While the assignment of hamartin and tuberin to specific signaling pathways is a major advance, it is still unclear how such alterations lead to the complex neurologic and non-neurologic manifestations seen in TSC. Downstream of mTORC1, activated phosphorylated-S6 kinase and phosphorylated-S6 regulate the translation of subsets of mRNAs. Loss of hamartin or tuberin may then cause dysregulated mRNA translation with a subset of these genes responsible for the phenotypes seen in TSC. Much more research is needed to identify genes regulated by TSC1/TSC2 and how their specific dysfunction affects brain development and homeostasis.

\section{Animal models}

The generation of rodent models was a critical advance to determine many facets of disease initiation and progression in TSC. As this review focuses on human neurodevelopmental disorders in TSC, animal models will not be discussed in great detail. However, recent reviews are available [27, 49].

Conventional knockout of the $T s c 1$ and $T s c 2$ genes in mice clearly established essential roles for both genes during embryonic development as early demise was seen prior to any substantive brain development $[50,51]$. Further support for these findings comes from analyses of the Eker rat, a well studied model for kidney tumorigenesis. The Eker rat has a high penetrance of kidney tumors and is due to the heterozygous inactivation of the rat $T s c 2$ gene [52]. Similar to mice, rats with homozygous loss of their Tsc2 gene have an early embryonic lethal phenotype.

The generation of conditional knockout ( $\mathrm{CKO}$ ) mice using the Cre-LoxP system was used to determine the contribution of the $T s c l$ gene to brain development. $T s c 1^{\text {GFAP }}$ CKO mice were produced by inactivation of the Tscl gene in astrocytes [53] while Tsc1 $1^{\text {Synapsin }}$ CKO [54] and $T s c 1^{\text {CamKII }}$ CKO mice [45] have Tscl gene inactivation restricted to post-mitotic neurons. Additional models using this approach are needed. For example, the dramatic response of infantile spasms to vigabatrin in patients with
TSC suggests an underlying abnormality of GABAergic interneurons. Future animal models targeting these critical neurons may offer much insight to the pathogenesis of these often devastating seizures.

In addition to Tscl models described above, the conditional knockout of the mouse $T s c 2$ gene in the brain was recently published [55]. This animal model also used the Cre-LoxP system to target neural progenitor cells. The mice had abnormalities of cortical development involving both neuronal and glial cell lineages. Increased mTORC1 activity was also seen.

Animal models have been invaluable for determining the contribution of the $T s c 1$ and $T s c 2$ genes to specific lineages of the brain and for preclinical testing of new therapeutics (see below). They do not however recapitulate many aspects of TSC including tuber or SEGA formation. It is not known is this is due to species-specific functions of the TSC genes in human versus mouse or whether the targeted populations of neural cells and/or the timing of gene inactivation are not optimal.

\section{Preclinical trials of mouse models with mTORC1 inhibitors}

The development of robust preclinical models of TSC coupled with assignment of hamartin/tuberin to control of mTORC1 activity quickly led to the hypothesis that treatment with rapamycin or similar agents could halt or even reverse the abnormalities seen in TSC. Tsc1 ${ }^{\text {GFAP }} \mathrm{CKO}$ mice are very well suited to test this hypothesis as their seizures increase in frequency over time and are linked with abnormalities of glutamate and potassium uptake from the synaptic cleft by astrocytes [56, 57]. These findings strongly support the role of astrocytes in epileptogenesis and also suggest similar abnormalities may exist in human tissues as well [58]. Zeng et al. treated $T_{s c 1}{ }^{\text {GFAP }}$ CKO mice with rapamycin and found prolongation of lifespan and a striking decrease in the number of seizures compared to $T s c 1^{\text {GFAP }}$ CKO mice treated only with vehicle [59]. This was seen if rapamycin was used before or even after seizure initiation suggesting that mTORC1 inhibition may act like a true "anti-epileptic" in this mouse model. This group further demonstrated that rapamycin treatment restored glutamate homeostasis with an increase in the expression of the astrocytic glutamate transporters, GLT-1 and GLAST. Withdrawal of rapamycin was associated with a return of symptoms and eventual demise of these mice. This suggests that if mTORC1 inhibitors become a viable therapy for patients with TSC, these drugs may need to be given continuously or in cycles.

Tscl ${ }^{\text {Synapsin }}$ CKO mice were also treated with rapamycin or RAD001, a related mTORC1 inhibitor [60]. Use of 
either agent increased survival and restored mTORC1 activity to levels seen in control brains. Furthermore, treatment with mTORC1 inhibitors restored AKT activation in the brains of $T_{s c 1} 1^{\text {Synapsin }} \mathrm{CKO}$ mice. This is an important finding as TSC1 or TSC2-deficient cells have impaired AKT activation due to loss of mTORC2 activity [61]. As activated AKT is a potent human oncogene, these findings may explain why the tumors seen in TSC are not malignant. The clinical use of mTORC1 inhibitors should then be viewed with some caution as this result suggests that mTORC1 inhibition may activate AKT and promote tumorigenesis. It should be stressed that this remains a theoretical concern for mTORC1 inhibitors that is not supported by any data from mouse models or when used by patients with TSC.

Finally, $T s c 2$ heterozygous conventional knockout mice were used to assess problems in learning and whether such abnormalities are mTORC1-dependent by response to rapamycin [45]. $T s c 2^{+/-}$mice do not have overt cortical or hippocampal structural abnormalities though a moderate increase in mTORC1 was seen. These findings in $T s c 2^{+/-}$ mice were correlated with behavioral studies showing impaired long term potentiation and deficiencies in hippocampus-dependent spatial memory assayed in the Morris water maze. Remarkably, rapamycin treatment normalized long term potentiation and restored spatial memory. These results suggest that even partial dysregulation of mTORC1 through haploinsufficiency may lead to cognitive deficits in patients with TSC and that even tuberless regions of the brain may contribute to neurological dysfunction. Similar results were previously reported in Tscl heterozygous conventional mice though reversibility through mTORC1 inhibition was not tested [44]. A recent report of rapamycin efficacy in mice with a neuronal loss of Pten (see Fig. 2) further supports than even in the absence of discrete cortical lesions, dysregulation of TSC/Rheb/ mTOR signaling can cause cognitive and social abnormalities [62].

\section{Clinical trials with mTORC1 inhibitors}

While therapies for patients with TSC have certainly progressed over the last century, we are still largely restricted to symptomatic treatment of epilepsy, autism, psychiatric disorders and mental retardation. As described above, identification of hamartin/tuberin in the control of mTORC1 signaling almost immediately led to the suggestion that rapamycin or related agents would be logical therapies to treat and possibly even prevent the severe neurological aspects of TSC. Application of rapamycin and RAD001 to preclinical animal models has further increased enthusiasm for such use.
Rapamycin (sirolimus) has been approved by the FDA since 1999 for immunosuppression in patients receiving kidney transplants. It has recently been used with adults who have kidney and lung manifestations of TSC or lymphangioleiomyomatosis (LAM), a genetically related disorder arising from somatic mutations in the TSC2 gene [63]. In these adult patients with TSC or LAM, kidney angiomyolipomas regressed in size and patients with lung disease appeared to have a stabilization of their disease compared to clear progression in patients treated with a placebo $[64,65]$. Side effects were generally benign and the drug was overall well tolerated.

To date, there have been two reports of rapamycin use for neurological disease in patients with TSC $[66,67]$. Both studies reported SEGA regression, likely circumventing the need for any neurosurgical intervention. These patients were younger than those in the TSC kidney and lung trials but also appeared to tolerate rapamycin therapy well.

These initial clinical results in kidney, lung and brain lesions were very promising and seem to validate their potential use in patients with TSC. However, all treatments with mTORC1 inhibitors reported to date were applied to progressive lesions that likely originated after birth. It is not known if mTORC1 inhibition can reverse abnormalities related to tubers and other abnormalities that arose during fetal development. However even if tubers are static structural lesions, the identification of altered glutamate homeostasis in Tsc1 ${ }^{\text {GFAP }}$ CKO mice for example raises the intriguing possibility that functional status of tubers to cause neurological disease may still be reversible through inhibition of mTORC1.

\section{Summary and future directions}

Amazing progress has been recently made in TSC research. However, fundamental questions about the relationship of TSC to neurodevelopmental disorders remain. Is autism and ASD in TSC due to the number or location of tubers? Are tubers even required for disease pathogenesis? Do seizures at a young age trigger autistic symptoms? Does loss of even one copy of the TSC1 or TSC2 genes cause neurological dysfunction due to haploinsufficiency? Is a "second hit" necessary in key brain regions to cause autism or epilepsy? The answers to these and other questions remain active areas of investigation and will require more sophisticated animal models of TSC and translational research to fully define the mechanism of abnormal brain development. Finally, are findings from TSC relevant to the millions of people worldwide with neurodevelopmental disorders that do not have TSC? It is possible that a shared mechanism of disrupted mTOR signaling may explain the significant overlap between patients with TSC and patients with 
autism or epilepsy. This intriguing possibility has received scant attention though variations in genes involved in phosphatidylinositol/mTOR signaling (INPP1, PIK3CG, TSC2) have been identified in children with autism [68]. Direct evidence for involvement of this pathway in the brains of children with autism is lacking though the existing data is limited to one series of 5 patients examined for phosphorylated-S6 levels in postmortem frontal cortex and cerebellum [69]. Further experiments exploring mTOR signaling abnormalities in patients with isolated autism or epilepsy need to be undertaken. If such abnormalities exist, clinical trials using mTORC1 inhibitors may establish new therapeutic approaches for these devastating disorders.

Acknowledgements Dr. Ess receives research funding from the NINDS, NIH and the Tuberous Sclerosis Alliance. He would like to thank Dr. Pat Levitt for his support. In addition, he would also like to thank individuals with TSC as well as their families for inspiration and motivation.

\section{References}

1. O'Callaghan FJ. Tuberous sclerosis. BMJ. 1999;318(7190):1019-20.

2. Crino PB, Nathanson KL, Henske EP. The tuberous sclerosis complex. N Engl J Med. 2006;355(13):1345-56.

3. McClintock WM. Neurologic manifestations of tuberous sclerosis complex. Curr Neurol Neurosci Rep. 2002;2(2):158-63.

4. Pampiglione G, Pugh E. Letter: infantile spasms and subsequent appearance of tuberous sclerosis syndrome. Lancet. 1975;2 (7943):1046.

5. Pampiglione G, Moynahan EJ. The tuberous sclerosis syndrome: clinical and EEG studies in 100 children. J Neurol Neurosurg Psychiatry. 1976;39(7):666-73.

6. Elterman RD, Shields WD, Mansfield KA, Nakagawa J. Randomized trial of vigabatrin in patients with infantile spasms. Neurology. 2001;57(8):1416-21.

7. Levitt P. Disruption of interneuron development. Epilepsia. 2005;46(Suppl 7):22-8.

8. de Vries PJ, Prather PA. The tuberous sclerosis complex. N Engl J Med. 2007;356(1):92. author reply 3-4.

9. Critchley M, Earl C. Tuberose sclerosis and allied conditions. Brain. 1932;55:311-46.

10. Curatolo P, Porfirio MC, Manzi B, Seri S. Autism in tuberous sclerosis. Eur J Paediatr Neurol. 2004;8(6):327-32.

11. Wiznitzer M. Autism and tuberous sclerosis. J Child Neurol. 2004;19(9):675-9.

12. Muhle R, Trentacoste SV, Rapin I. The genetics of autism. Pediatrics. 2004;113(5):e472-86.

13. Au KS, Williams AT, Roach ES, Batchelor L, Sparagana SP, Delgado MR, et al. Genotype/phenotype correlation in 325 individuals referred for a diagnosis of tuberous sclerosis complex in the United States. Genet Med. 2007;9(2):88-100.

14. de Vries PJ, Hunt A, Bolton PF. The psychopathologies of children and adolescents with tuberous sclerosis complex (TSC): a postal survey of UK families. Eur Child Adolesc Psychiatry. 2007;16(1):16-24.

15. Joinson C, O'Callaghan FJ, Osborne JP, Martyn C, Harris T, Bolton PF. Learning disability and epilepsy in an epidemiological sample of individuals with tuberous sclerosis complex. Psychol Med. 2003;33(2):335-44.
16. Jay V. Historical contributions to pediatric pathology: Tuberous sclerosis. Pediatr Dev Pathol. 1999;2(2):197-8.

17. von Recklinghausen F. Ein Herz von einem Neugeborene welches mehrere theils nach aussen, theils nach den Höhlen prominirende Tumoren (Myomen) trug. Monatschr Geburtsheilkd. 1862;20:1-2.

18. Bourneville DM. Tuberous sclerosis with cortical abnormalities: mental retardation and hemiplegic epilepsy. Archives de neurologie. 1880;1:81-91.

19. Bourneville D, Brissard E. Encéphalite ou sclérose tubéreuse des circonvolutions cérébrales. Archives de neurologie. 1881;1:390-412.

20. Vogt H. Zur Diagnostik der tuberösen Sklerose. Zeitschrift für die Erforschung und Behandlung des jugendlichen Schwachsinns auf wissenschaftlicher Grundlage. Jena. 1908;2:1-16.

21. Gomez MR, Kuntz NL, Westmoreland BF. Tuberous sclerosis, early onset of seizures, and mental subnormality: study of discordant homozygous twins. Neurology. 1982;32(6):604-11.

22. Lagos JC, Gomez MR. Tuberous sclerosis: reappraisal of a clinical entity. Mayo Clin Proc. 1967;42(1):26-49.

23. Gomez MR. Tuberous Sclerosis. 2nd ed. ed: Raven Press; 1988.

24. Moolten SE. Hamartial nature of tuberous sclerosis complex and its bearings on the tumor problem: report of a case with tumor anomaly of the kidney and adenoma sebaceum. Arch Intern Med. 1942;69:589-623.

25. Kanner L. Autistic disturbances of affective contact. Nerv Child. 1943;2:217-50w.

26. Ess KC, Uhlmann EJ, Li W, Li H, Declue JE, Crino PB, et al. Expression profiling in tuberous sclerosis complex (TSC) knockout mouse astrocytes to characterize human TSC brain pathology. Glia. 2004;46(1):28-40.

27. Holmes GL, Stafstrom CE. Tuberous sclerosis complex and epilepsy: recent developments and future challenges. Epilepsia. 2007;48(4):617-30.

28. Park SH, Pepkowitz SH, Kerfoot C, De Rosa MJ, Poukens V, Wienecke R, et al. Tuberous sclerosis in a 20-week gestation fetus: immunohistochemical study. Acta Neuropathol. 1997;94(2):180-6.

29. Wei J, Li P, Chiriboga L, Mizuguchi M, Yee H, Miller DC, et al. Tuberous sclerosis in a 19-week fetus: immunohistochemical and molecular study of hamartin and tuberin. Pediatr Dev Pathol. 2002;5(5):448-64.

30. Bolton PF. Neuroepileptic correlates of autistic symptomatology in tuberous sclerosis. Ment Retard Dev Disabil Res Rev. 2004;10 (2):126-31.

31. Bolton PF, Griffiths PD. Association of tuberous sclerosis of temporal lobes with autism and atypical autism. Lancet. 1997;349 (9049):392-5.

32. Wong V, Khong PL. Tuberous sclerosis complex: correlation of magnetic resonance imaging (MRI) findings with comorbidities. J Child Neurol. 2006;21(2):99-105.

33. Weber AM, Egelhoff JC, McKellop JM, Franz DN. Autism and the cerebellum: evidence from tuberous sclerosis. J Autism Dev Disord. 2000;30(6):511-7.

34. Eluvathingal TJ, Behen ME, Chugani HT, Janisse J, Bernardi B, Chakraborty $\mathrm{P}$, et al. Cerebellar lesions in tuberous sclerosis complex: neurobehavioral and neuroimaging correlates. J Child Neurol. 2006;21(10):846-51.

35. Ess KC, Kamp CA, Tu BP, Gutmann DH. Developmental origin of subependymal giant cell astrocytoma in tuberous sclerosis complex. Neurology. 2005;64(8):1446-9.

36. Buccoliero AM, Franchi A, Castiglione F, Gheri CF, Mussa F, Giordano F, et al. Subependymal giant cell astrocytoma (SEGA): is it an astrocytoma? Morphological, immunohistochemical and ultrastructural study. Neuropathology. 2009;29(1):25-30.

37. Sanai N, Tramontin AD, Quinones-Hinojosa A, Barbaro NM, Gupta N, Kunwar S, et al. Unique astrocyte ribbon in adult human brain contains neural stem cells but lacks chain migration. Nature. 2004;427(6976):740-4. 
38. Berg H. Vererbung der tuberösen Sklerose durch zwei bzw. drei Generationen. Z ges Neurol Psychiatr. 1913;19:528-39.

39. van Slegtenhorst M, de Hoogt R, Hermans C, Nellist M, Janssen $\mathrm{B}$, Verhoef $\mathrm{S}$, et al. Identification of the tuberous sclerosis gene TSC1 on chromosome 9q34. Science. 1997;277(5327):805-8.

40. Consortium ECTS. Identification and characterization of the tuberous sclerosis gene on chromosome 16. Cell. 1993;75(7):1305-15.

41. Sancak O, Nellist M, Goedbloed M, Elfferich P, Wouters C, Maat-Kievit A, et al. Mutational analysis of the TSC1 and TSC2 genes in a diagnostic setting: genotype-phenotype correlations and comparison of diagnostic DNA techniques in Tuberous Sclerosis Complex. Eur J Hum Genet. 2005;13(6):731-41.

42. Wang JY, Knudsen ES, Welch PJ. The retinoblastoma tumor suppressor protein. Adv Cancer Res. 1994;64:25-85.

43. Henske EP, Scheithauer BW, Short MP, Wollmann R, Nahmias J, Hornigold $\mathrm{N}$, et al. Allelic loss is frequent in tuberous sclerosis kidney lesions but rare in brain lesions. Am J Hum Genet. 1996;59(2):400-6.

44. Goorden SM, van Woerden GM, van der Weerd L, Cheadle JP, Elgersma Y. Cognitive deficits in Tsc1+/- mice in the absence of cerebral lesions and seizures. Ann Neurol. 2007;62(6):648-55.

45. Ehninger D, Han S, Shilyansky C, Zhou Y, Li W, Kwiatkowski DJ, et al. Reversal of learning deficits in a Tsc2+/- mouse model of tuberous sclerosis. Nat Med. 2008;14(8):843-8.

46. Kwiatkowski DJ. Rhebbing up mTOR: new insights on TSC1 and $\mathrm{TSC} 2$, and the pathogenesis of tuberous sclerosis. Cancer Biol Ther. 2003;2(5):471-6.

47. Mak BC, Yeung RS. The tuberous sclerosis complex genes in tumor development. Cancer Invest. 2004;22(4):588-603.

48. Sarbassov DD, Ali SM, Kim DH, Guertin DA, Latek RR, Erdjument-Bromage $\mathrm{H}$, et al. Rictor, a novel binding partner of mTOR, defines a rapamycin-insensitive and raptor-independent pathway that regulates the cytoskeleton. Curr Biol. 2004;14 (14):1296-302.

49. Ess KC. Modeling tuberous sclerosis complex: Brain development and hyperexcitability. In: Baraban SC, editor. Animal models of epilepsy: methods and innovations. NY: Humana Press; 2009.

50. Kobayashi T, Minowa O, Sugitani Y, Takai S, Mitani H, Kobayashi E, et al. A germ-line Tsc1 mutation causes tumor development and embryonic lethality that are similar, but not identical to, those caused by Tsc 2 mutation in mice. Proc Natl Acad Sci USA. 2001;98(15):8762-7.

51. Onda H, Lueck A, Marks PW, Warren HB, Kwiatkowski DJ. Tsc2 $(+/-)$ mice develop tumors in multiple sites that express gelsolin and are influenced by genetic background. J Clin Invest. 1999;104 (6):687-95.

52. Kobayashi T, Hirayama Y, Kobayashi E, Kubo Y, Hino O. A germline insertion in the tuberous sclerosis (Tsc2) gene gives rise to the Eker rat model of dominantly inherited cancer. Nat Genet. 1995;9(1):70-4.

53. Uhlmann EJ, Wong M, Baldwin RL, Bajenaru ML, Onda H, Kwiatkowski DJ, et al. Astrocyte-specific TSC1 conditional knockout mice exhibit abnormal neuronal organization and seizures. Ann Neurol. 2002;52(3):285-96.

54. Meikle L, Talos DM, Onda H, Pollizzi K, Rotenberg A, Sahin M, et al. A mouse model of tuberous sclerosis: neuronal loss of Tsc1 causes dysplastic and ectopic neurons, reduced myelination, seizure activity, and limited survival. J Neurosci. 2007;27(21):5546-58.

55. Way SW, McKenna J 3rd, Mietzsch U, Reith RM, Wu HC, Gambello MJ. Loss of Tsc2 in radial glia models the brain pathology of tuberous sclerosis complex in the mouse. Hum Mol Genet. 2009;18(7):1252-65.

56. Jansen LA, Uhlmann EJ, Crino PB, Gutmann DH, Wong M. Epileptogenesis and reduced inward rectifier potassium current in tuberous sclerosis complex-1-deficient astrocytes. Epilepsia. 2005;46(12):1871-80.

57. Wong M, Ess KC, Uhlmann EJ, Jansen LA, Li W, Crino PB, et al. Impaired glial glutamate transport in a mouse tuberous sclerosis epilepsy model. Ann Neurol. 2003;54(2):251-6.

58. Sosunov AA, Wu X, Weiner HL, Mikell CB, Goodman RR, Crino PD, et al. Tuberous sclerosis: a primary pathology of astrocytes? Epilepsia. 2008;49(Suppl 2):53-62.

59. Zeng LH, Xu L, Gutmann DH, Wong M. Rapamycin prevents epilepsy in a mouse model of tuberous sclerosis complex. Ann Neurol. 2008;63(4):444-53.

60. Meikle L, Pollizzi K, Egnor A, Kramvis I, Lane H, Sahin M, et al. Response of a neuronal model of tuberous sclerosis to mammalian target of rapamycin (mTOR) inhibitors: effects on mTORC1 and Akt signaling lead to improved survival and function. J Neurosci. 2008;28(21):5422-32.

61. Huang J, Dibble CC, Matsuzaki M, Manning BD. The TSC1TSC2 complex is required for proper activation of mTOR complex 2. Mol Cell Biol. 2008;28(12):4104-15.

62. Zhou J, Blundell J, Ogawa S, Kwon CH, Zhang W, Sinton C, et al. Pharmacological inhibition of mTORC1 suppresses anatomical, cellular, and behavioral abnormalities in neural-specific Pten knock-out mice. J Neurosci. 2009;29(6):1773-83.

63. Strizheva GD, Carsillo T, Kruger WD, Sullivan EJ, Ryu JH, Henske EP. The spectrum of mutations in TSC1 and TSC2 in women with tuberous sclerosis and lymphangiomyomatosis. Am J Respir Crit Care Med. 2001;163(1):253-8.

64. Davies DM, Johnson SR, Tattersfield AE, Kingswood JC, Cox JA, McCartney DL, et al. Sirolimus therapy in tuberous sclerosis or sporadic lymphangioleiomyomatosis. N Engl J Med. 2008;358 (2):200-3.

65. Bissler JJ, McCormack FX, Young LR, Elwing JM, Chuck G, Leonard JM, et al. Sirolimus for angiomyolipoma in tuberous sclerosis complex or lymphangioleiomyomatosis. N Engl J Med. 2008;358(2):140-51.

66. Koenig MK, Butler IJ, Northrup H. Regression of subependymal giant cell astrocytoma with rapamycin in tuberous sclerosis complex. J Child Neurol. 2008;23(10):1238-9.

67. Franz DN, Leonard J, Tudor C, Chuck G, Care M, Sethuraman G, et al. Rapamycin causes regression of astrocytomas in tuberous sclerosis complex. Ann Neurol. 2006;59(3):490-8.

68. Serajee FJ, Nabi R, Zhong H, Mahbubul Huq AH. Association of INPP1, PIK3CG, and TSC2 gene variants with autistic disorder: implications for phosphatidylinositol signalling in autism. J Med Genet. 2003;40(11):e119.

69. Eberhart CG, Copeland J, Abel TW. Brief report: S6 ribosomal protein phosphorylation in autistic frontal cortex and cerebellum: a tissue array analysis. J Autism Dev Disord. 2006;36(8):1131-5.

70. Bai X, Ma D, Liu A, Shen X, Wang QJ, Liu Y, et al. Rheb activates mTOR by antagonizing its endogenous inhibitor, FKBP38. Science. 2007;318(5852):977-80.

71. Sun Y, Fang Y, Yoon MS, Zhang C, Roccio M, Zwartkruis FJ, et al. Phospholipase D1 is an effector of Rheb in the mTOR pathway. Proc Natl Acad Sci U S A. 2008;105(24):8286-91.

72. Ess K. Tuberous sclerosis complex: a brave new world? Current Opinion in Neurology. 2009 